\title{
Is a Rose Really Just as Sweet? Editorial: On Becoming "Research on Child and Adolescent Psychopathology"
}

\author{
Paul J. Frick ${ }^{1}$ \\ Accepted: 4 October 2020 / Published online: 28 December 2020 \\ (c) Springer Science+Business Media, LLC, part of Springer Nature 2020
}

\begin{abstract}
The current editorial outlines the reasoning that went into changing the name of the Journal of Abnormal Child Psychology to Research on Child and Adolescent Psychopathology. Connotations of the term "abnormal" have changed, since it was first used for the journal title in 1973. It is now frequently interpreted as describing the person, and not the condition that he or she has. It also does not currently promote the view that the person needs professional intervention but is often interpreted as indicating that the person is defective in some way. The new name of the journal was not intended to promote any single way of conceptualizing mental health problems but to provide a name that captures the significant distress and impairment experienced by persons with serious psychological difficulties, recognizes the need for professional intervention for these individuals, and attempts to minimize potential harmful effects of labelling. This name change is embedded in a broader appeal for mental health professionals to be sensitive to how labels can reinforce the stigma associated with mental health problems and to work to change the stigma that is associated with such problems in most modern societies.
\end{abstract}

Keywords mental health stigma $\cdot$ psychopathology $\cdot$ abnormal $\cdot$ child $\cdot$ adolescent

\section{Is a Rose Just as Sweet? Editorial: on Changing the Name of the Journal}

Mental health problems carry a stigma in most modern societies that mental health professionals can and should play an important role in reducing (Corrigan and Penn 1999). This stigma has a number of very pernicious consequences, such exacerbating the effects of the mental health problems on persons suffering from these conditions through self-stigmatization, creating obstacles for persons seeking needed treatment by being perceived by the individual as admitting to a personal failure, and limiting future opportunities for educational and occupational advancement due to misconceptions by others regarding the causes and consequences of mental health problems (Corrigan 2018; Hinshaw and Stier 2008). The effects of stigma on mental health problems are particularly concerning in children and adolescents, where self-stigmatization during a period crucial for identity development can have

Paul J. Frick

pfrick@1su.edu

1 Department of Psychology, Louisiana State University, 208 Audubon Hall, Baton Rouge, LA 70803, USA especially serious and long lasting effects on the individual (Hinshaw and Stier 2008).

Given this clear risk associated with stigma, it is irresponsible for us, as mental health professionals, to not consider the effects of the labels we use to describe the persons we study and treat. We cannot simply consider the most accurate and descriptive labels for the constructs we study, diagnose, and treat but we must also consider how the name will be perceived by others. Also, like many attitudes, we need to examine and subject to careful scrutiny our own. For example, in my experience, many mental health professionals are reluctant to give diagnoses of Oppositional Defiant Disorder or Conduct Disorder because it "blames the child for problems in his or her family". Implicit in this concern is that assigning a diagnosis constitutes "blaming the child" for it.

It is also clear that we need labels in science to classify the problems we study in a manner that allows for replication and to document the need for treatment. As a result, labels can have beneficial effects. To illustrate this, Boccaccini et al. (2008) used vignettes describing expert testimony that were read by 891 jury-pool members to determine how the description of antisocial behavior and diagnostic labels used to describe such behavior influenced their decisions on a hypothetical case of a juvenile defendant. They reported 
findings showing that descriptions of the antisocial behavior had stronger negative effects on decisions (e.g., greater perceptions of risk to others, warranting more severe punishment) than did the diagnostic labels themselves (e.g., conduct disorder). Most importantly, the use of the term "disorder" led to greater perceptions of the need for treatment for the juvenile defendant and the youth's potential to benefit from treatment. Thus, labels for mental health problems are important for conveying to others that a condition can lead to great impairment and suffering in an individual and requires intervention by trained mental health professionals. As result, labels that minimize distress and disability in an attempt to "normalize" mental health problems run the risk of being insensitive to the painful experiences of persons with serious mental health problems and their clear need for something more than a helping hand from a friend or family member or the need simply to "pull themselves up by the boot-straps" and get over it.

This need to capture a sweet spot in labelling mental health problems became apparent in my recent work on the American Psychiatric Association's DSM-5 Workgroup for ADHD and the Disruptive Behavior Disorders, where we developed a specifier for the diagnosis of Conduct Disorder based on research showing that callous and unemotional traits (e.g., lack of guilt, callous-lack of empathy, failure to put forth adequate effort into important activities; constricted emotional expression) designated a clinically and etiologically important subgroup of children with this disorder (Frick et al. 2014). After carefully developing the criteria based on the extant research, then came the task of deciding what to call this specifier, which is defined by characteristics that most would consider undesirable. We rejected terms that were not clear and descriptive and could cause confusion as to the nature of the construct (e.g., undersocialized). We rejected terms that had the potential for such stigma that it would outweigh any diagnostic benefit of the label or would lead people to avoid its use for fear of the potential consequences to the person being diagnosed (e.g., psychopathic). However, we also rejected terms that seemed to describe normative behavior, which did not convey the serious impairment associated with atypical levels of these traits and ran the risk of having clinicians over-diagnose children who are not in need of treatment (e.g., uncaring features). This careful deliberation resulted in the choice that is included the DSM-5 (American Psychiatric Association 2013), which was also chosen by ICD-11 (World Health Organization 2019); the specifier was called "With Limited Prosocial Emotions". The success of this naming process to minimize iatrogenic effects remains an open question (Edens et al. 2017; Prasad and Kimonis 2018).

Another difficulty with labels for mental health conditions is that how they are perceived by others can change over time. There is no better example of this than the term "mental retardation" that was introduced to replace such terms as "simpleton", "moron" and "imbecile" but, over the decades of its inclusion in the education and psychiatric nomenclature, it also became a term of ridicule (Harris 2010). As result, this condition is now referred to as "Intellectual Disability" (American Psychiatric Association 2013), in an attempt to continue to document the need for services for persons with this mental health condition, while avoiding the previous label that no longer carried the desired connotations from others.

This is where we find ourselves with the Journal of Abnormal Child Psychology. Since 1973, and its founding by Herb Quay, the journal has been a primary outlet for research on the most common psychological disorders affecting children and adolescents. It has published research that has contributed greatly to advances in both theory and practice that have helped to alleviate the suffering of a significant number of young persons with various forms of emotional and behavioral problems. This original name appropriately conveyed for many decades the primary scope of the journal, which focused on conditions that led to experiences that were quite different from those experienced by typically developing children and adolescents. It recognized the distressing and impairing nature of these conditions, promoting research that sought to advance knowledge on the epidemiology, etiology, assessment, treatment, prognosis, and developmental course of these clinical conditions. Further, the name reflected the goal of Herb Quay to be similar to the Journal of Abnormal Psychology, the premier outlet for research on psychopathological conditions across the lifespan since 1925 , but to focus specifically on these conditions as they develop prior to adulthood. Yet, over time, the term "abnormal" developed an increasingly pejorative connotation. It became interpreted as describing the person, and not the condition that he or she has. To call someone "abnormal" currently does not evoke empathy or concern nor does it promote the view that the person needs professional intervention. Instead, it suggests that the person is defective rather than afflicted. Thus, it is time to change the name of the journal.

With this first issue of 2021, the Journal of Abnormal Child Psychology has a new name. It is now called Research on Child and Adolescent Psychopathology. This new name does not require a single change in the journal's scope. Specifically, the journal's scope remains the following:

"The Journal of Abnormal Child Psychology brings together the latest innovative research that advances knowledge of psychopathology from infancy through adolescence. The journal publishes studies that have a strong theoretical framework and use a diversity of methods, with an emphasis on empirical studies of the major forms of psychopathology found in childhood 
disorders (e.g., disruptive behavior disorders, depression, anxiety, and autism spectrum disorder). Studies focus on the epidemiology, etiology, assessment, treatment, prognosis, and developmental course of these forms of psychopathology. Studies highlighting risk and protective factors; the ecology and correlates of children's emotional, social, and behavior problems; and advances in prevention and treatment are featured."

The new name recognizes that the journal's focus remains on conditions that can be highly distressing and impairing for children and adolescents and that clearly warrant professional intervention. This choice of title avoided using terms that could be viewed as being overly medical, such as "illness" and "disease". It reflects current practice in psychological research, using similar terms to refer to mental health conditions as other prominent journals in the field, such as Development and Psychopathology, Journal of Psychopathology and Behavioral Assessment, and Journal of Experimental Psychopathology. Further, it brings the journal in line with the name of the International Society for Research in Child and Adolescent Psychopathology, the research society for which this is the official journal.

I recognize that some may have concerns about even the term "psychopathology" connoting too much of a medical model view of psychological conditions by suggesting that the source of "pathology" is necessarily within the child. That was not our intention. We did not adopt the term "psychopathology" to endorse any single method for conceptualizing mental health conditions in children and adolescents. We at the journal want to provide the best science possible to inform this important and ongoing debate over how best to conceptualize mental health problems in ways that promote both research and treatment (Beauchaine and Hinshaw 2020; Sanislow et al. 2010). However we want to do it in way that is sensitive to the fact that mental health conditions are associated with stigma. We want to recognize the critical needs of the children and adolescents that are the focus of the research we publish, while still appreciating that the labels we use can be harmful to them. We know that current practice may change and such changes may necessitate a future name change for the journal. However, it is my sincere hope that the journal will be open to such changes, if it allows it to better fulfil its mission in a way that promotes the best science possible, while remaining on guard against the potential harmful effects of labels on the children and adolescents we study and seek to help.

\section{Compliance with Ethical Standards}

Ethical Approval The author certifies that this manuscripts was prepared in accordance with the ethical standards of the American Psychological Association.

\section{References}

American Psychiatric Association (2013). Diagnostic and statistical manual of mental disorders (5th ed.). Washington, DC: Author.

Beauchaine, T. P., \& Hinshaw, S. P. (2020). RDoC and psychopathology among youth: Misplaced assumptions and agenda for future research. Journal of Clinical Child and Adolescent Psychology, 49, 322-340.

Boccaccini, M. T., Murrie, D. C., Clark, J. W., \& Cornell, D. G. (2008). Describing, diagnosing, and naming psychopathy: How do youth psychopathy labels influence jurors? Behavioral Sciences and the Law, 26, 487-510.

Corrigan, P. W. (2018). Defining the stereotypes of health conditions: Methodological and practical considerations. Stigma and Health, 3, 131-138.

Corrigan, P. W., \& Penn, D. L. (1999). Lessons from social psychology on discrediting psychiatric stigma. American Psychologist, 54, 765-776.

Edens, J. F., Mowle, E. N., Clark, J. W., \& Magyar, M. S. (2017). "A psychopath by any other name?": Juror perceptions of the DMS-5 "Limited Prosocial Emotions" specifier. Journal of Personality Disorders, 30, 1-20.

Frick, P. J., Ray, J. V., Thornton, L. C., \& Kahn, R. E. (2014). Can callous-unemotional traits enhance the understanding, diagnosis, and treatment of serious conduct problems in children and adolescents? A comprehensive review. Psychological Bulletin, 140, $1-57$.

Harris, J. C. (2010). Intellectual disability: A guide for families and professionals. New York: Oxford University Press.

Hinshaw, S. P., \& Stier, A. (2008). Stigma as related to mental disorders. Annual Review of Clinical Psychology, 4, 367-393.

Prasad, A. H., \& Kimonis, E. R. (2018). Effects of the "Limited Prosocial Emotions" specifier for conduct disorder on juror perceptions of juvenile offenders. Criminal Justice and Behavior, 45, 1547-1564.

Sanislow, C. A., Pine, D. S., Quinn, K. J., Kozak, M. J., Garvey, M. A., Heinssen, R. K., et al. (2010). Developing constructs for psychopathology research: Research domain criteria. Journal of Abnormal Psychology, 119, 631-639.

World Health Organization (2019). International classification of diseases and related health problems (11th ed.). Geneva.

Publisher's Note Springer Nature remains neutral with regard to jurisdictional claims in published maps and institutional affiliations. 